\title{
Saviano, Garrone, Gomorrah: Neorealism and Noir in the Land of the Camorra
}

\author{
Fabrizio Cilento
}

\section{Unidentified Narrative Objects}

In the opening chapter of Gomorrah, Roberto Saviano describes the arrival of shipping containers from China loaded with dead bodies spilling out in the port of Naples. "The hatches, which had been improperly closed, suddenly sprang open, and dozens of bodies started raining down. They looked like mannequins. But when they hit the ground, their heads split open as if their skulls were real. And they were." Just a few lines later, Saviano reveals his source: "The port crane operator covered his face with his hands as he told me about it, eyeing me through his fingers. As if the mask of his hands might give him the courage to speak. He'd seen the bodies fall..." (2006:3-4).

This example illustrates how, throughout his personal journey into the realm of the Neapolitan-based organized crime system called Camorra, Saviano does not distinguish the author's subjective gaze from that of his unofficial sources. Instead, he creates an eye/I dynamic, that is, an oscillation between centered and autonomous subjectivity. The incorporation of unanticipated viewpoints such as that of the port crane operator allows Saviano to break the boundaries between the journalistic inquest, a whistleblower's account, and the political pamphlet. To embrace multiple identities is an ethical position, a rejection of a politically correct point of view on the Italian Southern Question.

Portrayed as an open, infected wound, the port of Naples constitutes a perfect location for revealing the global dealings of the Camorra. Such a setting is revelatory of the influence of American film noir and hard-boiled literature on Saviano. Recent studies by Gyan Prakash and Edward Dimendberg1 have discussed film noir's preoccupation with the urban landscape and dystopic images of the modern city. The liminal space of the port is topical in the history of noir: from the arrival of the freighter La Paloma in San Francisco's dock in The Maltese Falcon (John Huston, 1941) to films such as Port of New York (Laslo Bendek, 1949), to more recent neo-noirs such as The Usual Suspects (Bryan Singer, 1995).

The link with a noir imaginary is the peculiarity of Gomorrah and possibly a key factor in its success when compared to the large body of nonfiction reportages or academic books on organized crime. While a book on the Camorra would typically sell between 5,000 and 10,000 copies and rarely crossed the regional borders of Campania, Gomorrah became an instant bestseller translated in over fifty languages. On a contextual level Gomorrah is not radically different from previous books on the topic, which describe the illegal trafficking of the Camorra in similar ways. In fact, Saviano was accused of plagiarism in 2009 by freelance reporter Simone di Meo and by the local newspaper Corriere di Caserta (and then acquitted by the Naples courts the following year). Caught in the fiction vs. nonfiction debate on the nature of the book, critics overlook the author's stylistic choice of narrating actual events by adopting the language of global noir. The influence of noir on Saviano is clarified and even accentuated by Matteo Garrone's cinematic adaptation of Gomorrah. Garrone stated in numerous interviews that he first experienced a sinister attraction to the hyperreal 'images' that the book presents, such as the Chinese bodies with open skulls looking like mannequins, and only later became preoccupied with Saviano's overall analysis of the crime system. While the book is an epic attempt at describing the larger-than-life apparatus of an all-invasive conspiracy, and to 
coherently represent fragmented pieces of the unknown, the film is a complementary tool that proceeds by giving autonomy to a series of minor, and apparently secondary episodes. These scenes portray the invisible everyday life under the state-within-the state that criminality has constructed in the outskirts of Naples.

Because Saviano's book is neither a novel nor reportage, neither narrative nor journalism, in New Italian Epic Wu Ming defined it an UNO, that is "Unidentified Narrative Object" (2009: 12). Saviano uses police reports, judicial documents, and personal experiences to depict Naples' organized crime operations within the globalized economy. Again, what is unique is that Saviano blends these technical sources with the storytelling typical of the hard-boiled school of writing and film noir. This, and not the revelation of the naked facts, allowed him to reach both a specialist and a vast generalist audience. While there is certainly interest in the organized crime issue, not everyone is willing to decipher the heavy technicalities, to spot the recurrent falsifications in official documents, or to climb the bureaucratic jargon's wall of ice. Saviano managed to find a remarkable balance between the necessary evil of technicalities and an evocative noir language (which involve gruesome details and succinct anecdotes).

Saviano's narrative voice resembles that of an investigator who is both fascinated and repelled by crime. At times the author embodies an ultra-analytical and ultra-educated version of Sam Spade or Philip Marlowe, or better, of a Sam Spade and Philip Marlowe with an unprecedented sociopolitical awareness that leads into activism. But the author's voice in the book is also enigmatic at times. Some passages describe new lethal drugs being tested on heroin addicts, an indifferent crowd passing by the wounded dying in the streets, a crossfire killing of a fourteen-year-old girl, and primitive rituals for recruiting young teenagers into the crime organization and testing their courage. How was Saviano able to see all this? Who is the narrating "I"? Are we reading a piece of journalism, or a novel disguised as such? According to Wu Ming, this sort of question leads Gomorrah into the UNO. In order to understand this, as well as the transition from Saviano's Gomorrah to its film adaptation by Garrone, I propose to expand on the concept of Wu Ming's UNO, arguing that it should not be limited to literature, but can also be extended to Saviano himself as a result of his unprejudiced use of different media. The author himself can be considered an UNO, a ubiquitous storyteller in the age of media convergence and participatory culture. Saviano received numerous death threats, and was forced to live in seclusion under constant government protection, but this did not prevent his provocative ideas from simultaneously circulating on different media, throughout national newspapers, television, social networks, literary blogs, platforms such as YouTube, and theatrical and cinematic adaptations.

Garrone's film appears as an important extension of an innovative communication strategy rather than a close re-proposition of the original material. When Garrone started shooting Gomorrah, Saviano had already successfully raised awareness about the Camorra. Thus, the film is able to bypass much of the first hand informative and pedagogic material and to concentrate on a minimalist rather than "epic" approach. Gomorrah is an ambitious film that overcomes the present impasses of Italian neorealist heritage by blending it with noir moral ambiguity and visual culture. For this reason, Garrone's work is revelatory of how today film noir is a not a uniquely American cinematic phenomenon, but rather a transnational and transgeneric one, capable of crossing national boundaries and dramatizing the crisis of urban peripheries.

\section{Saviano in the Age of Convergence Culture}

After the publication of Gomorrah, Saviano appeared several times on television, interviewed by well-known journalists and talk show hosts such as Enzo Biagi (Rotocalco televisivo), Michele Santoro (Annozero), Enrico Mentana (Matrix), Daria Bignardi (Le invasioni barbariche and L'era glaciale), and Fabio Fazio (Che tempo fa and Vieni via con me, which he co-hosted). Saviano was also interviewed by Nazanine Moshiri on Al Jazeera's People \& Power (where he was labeled "the Italian Salman Rushdie"), by Laurence Pollard on BBC's Culture Show, and by NOS Netherlands, the Dutch national television. His communication strategy recalls that employed by Pier Paolo Pasolini, another intellectual who wanted to be seen protesting television on television and who used paid time to stage his ferocious polemics against the so-called "economic miracle" (1959-1964) and its afterwards.2 Saviano's monologues and interviews in the era of Silvio Berlusconi's failed "Italian miracle" and conflicts of interest are often self-reflexive, with the result that the medium itself is put on trial for the distorted information it provides. Organized criminality had never before been addressed with such precision, frontally challenged or described in such detail on TV. It is not surprising that these epiphanies made headlines on national newspapers, and that in the public opinion

the writer's persona quickly became inseparable from that of the public storyteller. This was also confirmed when in 
2009 Saviano received an honorary degree in Communication and Art Teaching from Milan's Academy of Fine Arts in Brera. Saviano dedicated the awards to the people from the south of Italy living in Milan, generating subsequent polemics with senator Roberto Castelli from the Northern League.

Saviano quickly transcended the literary object, or at least has demonstrated Gomorrah's capacity to exist simultaneously inside and outside the page. Seen in this light, Gomorrah appears to be an UNO not only for the literary techniques effectively described by Wu Ming, but especially for Saviano's capacity to transform a best-seller into a fluid work in progress that each time resists its detractors by refining its own arguments, or by choosing new objectives. Thus, the legitimate critiques regarding the role of the publisher (which emphasize the rigorous work of editor Helena Janeczek at Mondadori) or the accusations of plagiarism and inexactitudes are marginalized, since they miss the main point of Saviano's communication strategy. Furthermore, in the age of media convergence and participatory culture, the TV appearances continue to successfully circulate across different systems, once they are uploaded on platforms such as YouTube and social networks such as Facebook. Today Saviano is a writer as much as he is a ubiquitous storyteller, for security reasons physically separated from the community in which he grew up, but virtually present in it more than ever. He is a catalyst able to generate in-depth discussion and to bring to light what had been, before the "Gomorrah effect," conveniently removed from the Italian civil conscience for decades. Another proof of Saviano's pursuit of this strategy lies in the fact that he has chosen the dynamic essay form over the novel for The Beauty and Inferno (2009) and Vieni via con me (2011), which contains the stories that were presented in the TV program he co-hosted. While of course he may publish another UNO novel in the future, what is remarkable about Vieni via con me is that Saviano adapted texts originally conceived for television monologues into a book, and not vice-versa.

\section{Gomorrah Between Neorealism and Neo-Noir}

The elliptical and episodic cinematic adaptation of Gomorrah is the most significant step in its metamorphosis into a trans-media text. Garrone successfully blends Italian neorealism with film noir and its sci-fi derivations, creating another unique, unidentified object both in the panorama of contemporary Italian cinema and that of global neo-noir. It has been said that classic film noir has been conceived 'under the influence' of German expressionism, French poetic realism, and Italian neorealism. Historically, the fruitful relationship between noir and Italian cinema is as old as Obsession (1943) - Luchino Visconti's proto-neorealist 'dislocation' of James M. Cain's hard-boiled novel The Postman Always Rings Twice (1934). This is an early symptom of how the phenomenon of film noir is heterogeneous, polyglot, and indeed cosmopolitan. "Noir sensibility has, from the 1930 s to the present, articulated forms of emotional attachment beyond one's country of origins, and in its special relationship to a putatively universal 'modern man' forged in the shadow of global catastrophe" (Fay and Niedland 2010:2). Obsession's alienated characters are the product of exploitive and corrupt domestic relationships. Disguised as another image of American decadence and corruption, the foreignness of Cain's literary source allowed Visconti to indirectly critique the Fascist model of the patriarchal family as portrayed in the so-called "white telephones" films, a series of romantic comedies with elegant scenarios and aristocratic protagonists removed from the struggles of everyday life.

In turn, it would be difficult to overestimate the influence of neorealism on subsequent American film noir. This emerges in some of the most representative post-World War II American noirs such as Knock on Any Door (Nicholas Ray, 1949). Ray's film focuses on the dismal aspects of life and at times uses decadent exterior locations rather than studios. Furthermore, it denounces youth criminality (a topic that is also crucial in Gomorrah) as the product of a deranged social environment rather than of intrinsic human evil.

Gomorrah demonstrates how this tradition of elective affinities between Italian art cinema and film noir is still a vital tendency. Garrone's film is outstanding when compared to numerous the anti-mafia and anti-Camorra films produced in the last fifty years - a tendency animated by noble intents but at times plagued by disappointing results. 3 Instead, Gomorrah is informed by Paul Schrader's definitions of noir as "an uneasy, exhilarating combination of realism and expressionism" (1972:584), and "a moral vision of life based on style" (1972:591). As Porton wrote in a recent issue of Cineaste:

"Trained as a painter, Garrone possesses one of the sharpest eyes in contemporary cinema. Gomorrah teems with memorable 
compositions that offer visual equivalents to Saviano's more analytical perspective: the grotesque, if absurd, spectacle of naked gangsters tanning themselves in a solarium before a violent outburst interrupts their leisure as the film opens; a car swerving through a statuary park after another ghastly shoot out; two crazed kids emptying their machine guns on a beach; and a hapless truck driver splattered with toxic sludge" (2009:2).

If thematically Gomorrah pushes the limits of noir's pessimistic view of society, stylistically it involves numerous low-angle shots and an abundant use of the chiaroscuro technique. The latter constitutes a liberating choice that breaks any stereotypical view of Naples as "sun city." In this way Garrone's Naples echoes the Los Angeles depicted in movies such as Double Indemnity (Billy Wilder, 1944) and Blade Runner (Ridley Scott, 1982). In many long sequences such as the initiation ritual in a cave of the Camorra's young members, the city's outskirts appear shady, rebellious, dysfunctional, entrenched in ecological and racial crises, and above all paralyzed by organized criminality's internal wars. Moral and political authorities have vanished from the cursed territory with criminality rising to become "the system." This is perfectly integrated in the everyday life of a land in which victimization of the inhabitants is not the exception but the norm. In Gomorrah, monstrosity is something banal, almost natural (the only glimmer of hope for an alternate way of life appears in the few seconds in which a young character called Roberto rejects crime's logic and abandons the organization).

This appears to be an extension of a process initiated by classic noirs, which already presented a harsh account of capitalism. Film noir, with its private eyes, rogue cops, white-collar criminals, and femme fatales, reveals the collateral effects of American life. The criminal world cannot be conveniently isolated within the urban underworld as in the old gangster films of the 1930s because it flourishes everywhere. Every man is a potential criminal, and not even a quiet, anonymous life in suburbia is immune from violence. Film noir also undermines the cliché that in America there is always a second chance. "There is no reprieve in film noir, but characters just keep paying for their sins. In Joseph Lewis' Gun Crazy (1950), the focus was not on the victim but on the criminals themselves. One is compelled to share their fear and even their exhilaration. There was no moral compass anymore, to the point that even the audience is pulled into the action and becomes an accomplice" (Scorsese in A Personal Journey Through American Movies, 1995). What noir pointed at was a "moral denunciation in the name of basic values among which one finds the privilege accorded to relations of proximity and respect for ideal virtues to the detriment of material values," (Vernet 1993:36) which is often resolved in a courtroom or a police station. Gomorrah shares many of these same characteristics, from the lack of reprieve and a focus on the criminals, to the stylized lighting and composition. However, in the apocalyptic Gomorrah the traditional morals are absent, and there are no basic shared values to defend.

In transforming a 300-page book that contains an impressive amount of first-hand information into a two-hour film, Garrone and a small group of screenwriters, which initially included Saviano, deliberately rearrange chosen facts and proceed by subtraction. While the book has an international scope that involves Russia, Belarus, Scotland, the United States, Spain, the Middle East, and Colombia, the film follows just five main story lines. The protagonists are Pasquale, a master tailor who works in the black market to produce clothing for the high fashion labels that will go on to fit Hollywood stars; Don Ciro, whose duty is to deliver payments to the families of the accomplices who are in prison; Marco and Ciro, two teenagers obsessed with Scarface (Brian De Palma, 1983) who take Tony Montana as a role model; Maria (named Carmela Attrice in the book), murdered with the involvement of the thirteen-year old Totò for the betrayal of her secessionist son; and finally Franco, a toxic waste management specialist, and his young helper, Roberto. Through a brilliant montage á la Robert Altman,4 Garrone blends these stories together, touching upon different points of the Camorra's socioeconomic reach in a series of short cuts that develop simultaneously and at times intersect.

The common denominator of these stories lies in their allegorical value. The characters are executioners and at the same time victims manipulated by invisible forces. They live the illusion of cutting their own deals with the crime system, of bending its savagery to their own ends. Garrone focuses on the wretched of the earth: Camorra's daily laborers and foot soldiers operating in the suburbia. While minor in the book, these characters are elevated to protagonists. Despite the limited scope of the film, the idea of the Camorra as a global phenomenon is suggested through the presence of Nigerian and Chinese mafia (FIG.1), and by the superimposed text that appears at the end of the film, stating that the Camorra has invested in the rebuilding of the Twin Towers site. 


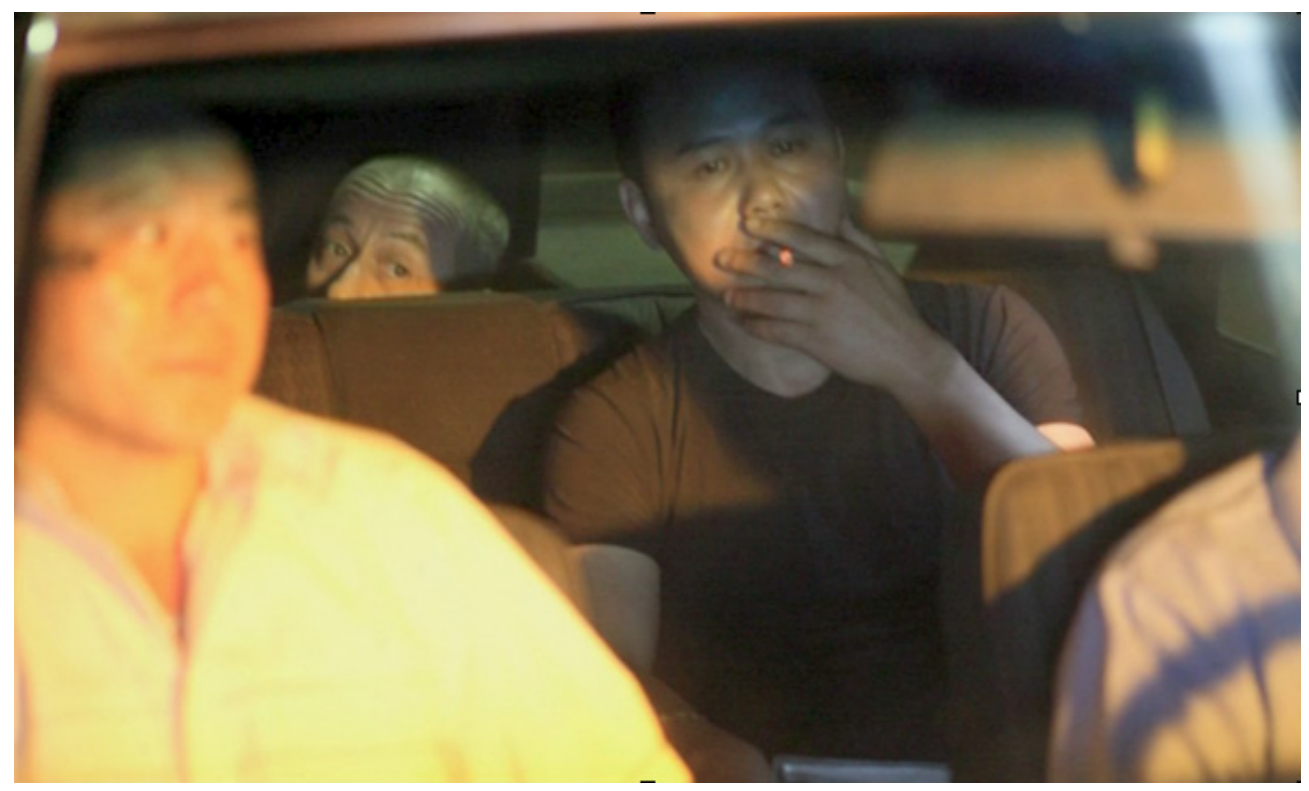

Figure 1. Xian and the Chinese driving the tailor Pasquale to an illegal factory.

A notable absence in the adaptation is that of Saviano's persona and his narrative "I" that emerges in many introspective chapters of Gomorrah, which could have been easily adapted in the film as a voice over. As Jameson pointed out in "Synoptic Chandler:"

"Both pulp or hard-boiled detective stories and film noir are indeed structurally distinguished by the fundamental fact that the voice-over, which signals in advance the closure of the events to be narrated just as surely as it marks the operative presence of an essentially radio aesthetic which has no equivalent in the earlier novel or silent cinema... It is at any rate clear that the voice over of the hard-boiled detective... offers a specifically radio pleasure which must be paid for by a kind of closure that allows the novels past tenses to resonate with doom and foreboding and marks the detective's daily life with the promise of adventure" (1993:36-37).

However, since Gomorrah is caught in a never-ending negative spiral dynamic, the closure of events brought by an authoritative voice becomes impossible. In Gomorrah there is no crime case to solve, no failure of the institutions to defend shared values, no struggle of an innocent individual, and thus no need for narrative closure. Everyone is, at a different level, involved and an accomplice in the system. Furthermore, we have explored how the narrative pleasure of Saviano's voice-over contextualizing shocking events has been a symbolic Trojan horse through the medium of television. As theorist Michel Chion in Audio-Vision has pointed out, television is essentially an auditory rather than a visual medium (1990:37). In order to satisfy his sociopolitical agenda, Saviano's monologues, the ultimate 'voice-over' of our civil conscience, audaciously construct a narration within the facts for his audience rather than simply commenting about the facts. Instead, Garrone has declared numerous times that he is not animated by such pedagogic and openly political impulses, privileging a stylized approach to the events instead.

Garrone's film problematizes cinema's representation of organized criminality, emphasizing that the battle of the Camorra is not fought exclusively at an economic level, but even more so at an imaginary level. In the chapter "Hollywood," Saviano describes how the resistible rise of a crime boss depends on the ability to instill a mix of terror and admiration in the local people through a vernacular appropriation of global cinema stars (which often becomes an involuntary parody). When it comes to the Camorra, it is life that imitates cinema, and not vice-versa: killers changed their way of holding a gun to imitate Quentin Tarantino's characters, a female boss nicknamed Nikita has bodyguards who dress in fluorescent yellow outfits like Uma Thurman in Kill Bill (2003), and Cosimo di Lauro's clothes are reminiscent of those of Brandon Lee's in The Crow (Alex Proyas, 1994). New generations of Camorra mimic cinematic villains in order to construct their own legend and present themselves as local heroes able to keep the order and to redeem the cursed territories surrounding Naples.

The idea of de-glamorizing Camorra is crucial in Garrone's adaptation: there are no elaborate weddings or 
summit meetings, but only a squalid, day-to-day struggle for survival. The incommensurable distance between Hollywood characters and the protagonists of Gomorrah emerges in the sequence in which Marco and Ciro quote passages of Scarface in an abandoned building at the city's edge (which belonged to the boss Walter Schiavone, who commissioned a replica of Tony Montana's villa as seen in De Palma's film). Rather than showing the mafia bosses in the film, Garrone concentrates on those at the bottom of the hierarchy. However, despite the fact that Gomorrah constitutes a new frontier in the brutal and raw representation of crime, there is no doubt that the film has appealed to younger generations of criminals. This hypothesis has been recently supported by a Northern Italian gang of teenagers in Quarto Oggiaro (Milan), whose members have been caught mimicking Marco and Ciro's poses and behaviors. Criminal teenagers shot cellular phone pictures of themselves in their underwear with a Kalashnikov pointed at the camera, an open homage the famous beach scene of Gomorrah (FIG. 2-3).
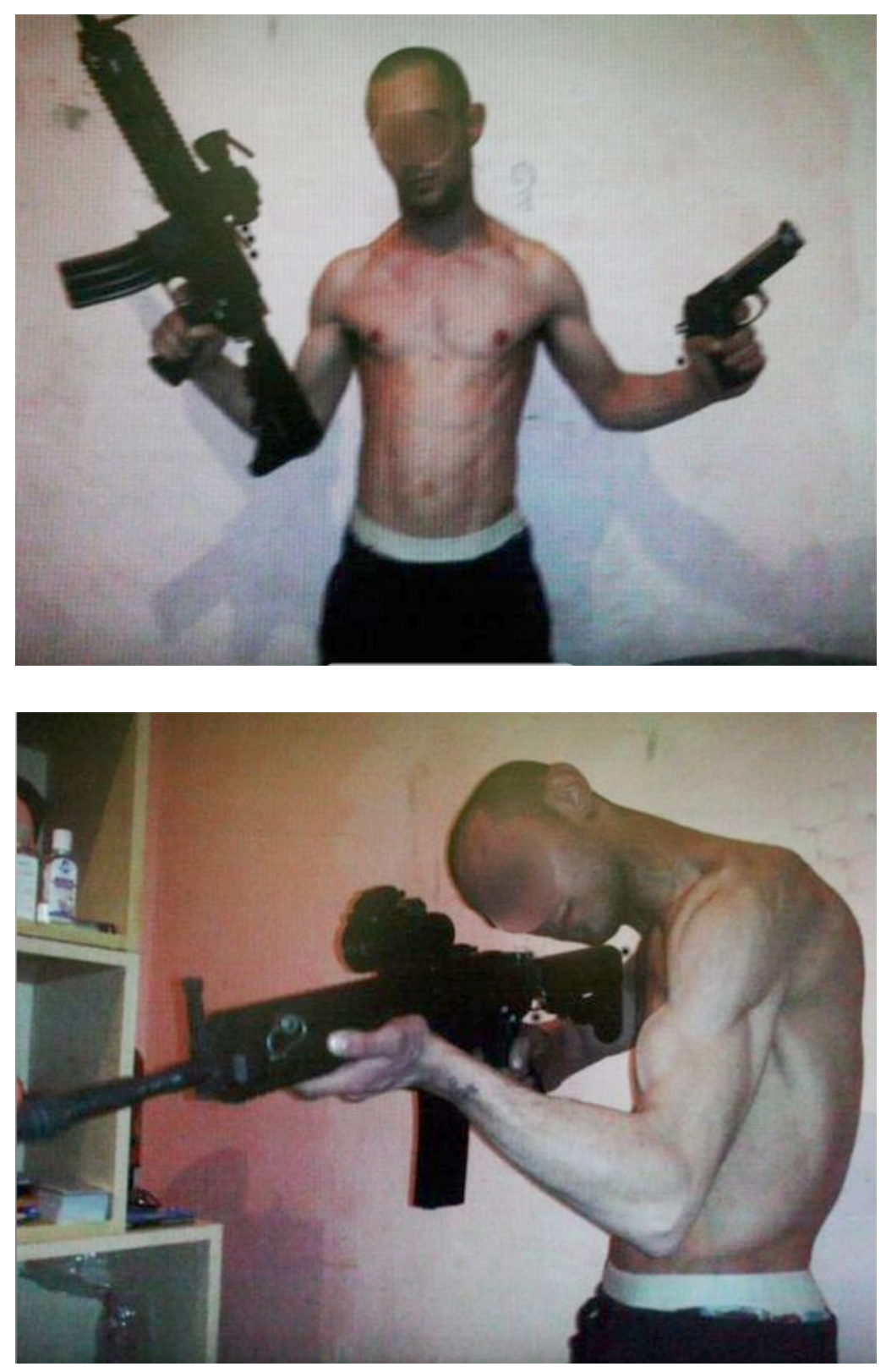

Figure 2-3. Life imitates cinema even when it comes to Gomorrah. Two cellular phone portrayals of a member of the Quarto Oggiaro gang. 
Although never complacent, Garrone is undoubtedly fascinated with the recent anthropological mutations of Neapolitan petty criminals. The rural background and association with banditry that marked the criminals a few decades ago has been washed away by the economic miracle, and supermodernity of the Neapolitan suburbia is surprising to international audiences. New generations of criminals, both in Gomorrah and in the pictures above, present a buzz haircut rather than a traditional hat, tattooed muscles pumped up by steroids, knockoff fashions, and the latest cell phones. To furnish an aesthetic portrayal of petty criminals is the project of the whole adaptation, which is not animated by the neorealist impulse to convey a pedagogic message or noir's need to solve the case.

What Garrone adopts from neorealism instead is a rigorous documentary-like style which emerges in the numerous sequences shot by a handheld camera. The operator is Garrone himself, who brings us unusually close to the criminals and in doing so incessantly interrogates what degree of "reality" is developing in front of the camera. Garrone creates a compelling link with the book by shooting on location in Scampia. Situated in the Neapolitan suburbia, the town is the largest open-air drug market in the world. In 2004 a bloody gang war erupted in the area between the controlling Di Lauro clan and a breakaway faction. The cinematic crew of Gomorrah aimed to reconstruct some of these dramatic events and was the first one allowed in the territory, which is considered a fortress in the hand of criminality, or a state within the state. However, at that time there was a tacit truce, a dynamic somewhat analogous to a dictatorship allowing UN inspections in their territories. In addition, for some drug dealers who appeared in the film playing themselves, Gomorrah represented a unique chance to fulfill their dream of becoming part of the cinematic world. Afterward, four were arrested for their crimes.

\begin{abstract}
"They were happy to participate in the film and share their experiences. To a certain extent, they were the first audience for the film, since they were always behind the monitor as I was shooting. They could tell me if a certain detail was correct. When I was shooting the scene with Toto and the drug dealer, the camera was at the top of the building. During the scene, an actual drug dealer, thinking the scene was real, came from the back to engage in an actual drug transaction. Then the drug dealer came and saw the scene on the monitor and advised us on how a drug deal should be conducted. In instances such as these, I was very concerned to get all the specifics correct...Since they had grown up in this environment, they weren't aware that it was anything abnormal" (Garrone in Porton 2009:6).
\end{abstract}

The heritage of masterpieces such as Roberto Rossellini’s so-called "war trilogy" (1945-48), Salvatore Giuliano (Francesco Rosi, 1961), and The Battle of Algiers (Gillo Pontecorvo, 1966), emerges in long uncut sequences, the use of natural lighting and of dialect, a degree of guided improvisation, and a mix of professional (the star Tony Servillo) and non-professional actors on set, chosen according to the principle of typecasting. These choices are particularly effective in the scenes set in "Le Vele," the infamous pyramid-shaped complex surrounded by dioxin-sprayed fields, a symbol of the country's different economic synchronies and of the permanence of the Third World within the First World. Here we finally visualize what we had only read in Saviano's work: the Neapolitan junkspace, the convenient black hole which hides what the Northern part of the peninsula does not want to see, eat, or above all, breathe.

Garrone gives a personal touch to the original material when he mixes the neorealist heritage with a sci-fi and neo-noir aesthetic. This conveys the uncanny feeling of incredulity that one experiences while reading Gomorrah for the first time, since Saviano's reconstituted reportage seems to come from another, deranged planet. The film's prelude is programmatic in this sense, and it reveals that Gomorrah will not be yet another neo-neo-neorealist film, 5 but a work that revitalizes the national tradition from within. In order to do so Garrone opportunistically employs the use of lighting and the dystopian feel of Blade Runner, the aesthetic use of graphic violence of HardBoiled (John Woo, 1992), and the dark irony and narrative twists of The Usual Suspects. Like Singer's film (which in turn constructs on a wave of 1970s conspiracy films),6 Gomorrah describes a potentially infinite network and "effectively exacerbates the ultimate question of the location of power...the apparent intuition that power may not be localizable, or at the very least that is so ceaselessly mobile that you can never assuredly point your finger directly at it" (Larsen 2002:17). We have seen how, differently from an early neorealist film such as Rossellini's Open City (1945) that presents a stark division between good and evil, or even differently from a film noir, in which the borders between good and evil are blurred, in Gomorrah it is not clear who the villains are and who we are supposed to empathize with, because there are no immediate alternatives (neither the detective nor Saviano as the investigative journalist) to the all-pervasive criminal system.

This is evident in the opening sequence of the film, in which we witness a triple execution in cold blood taking place in the claustrophobic space of a suburban tanning salon for reasons that are never revealed. Over a mechanical sound, the sinister figure of an avenger emerges in a medium shot from the blue artificial light of a solarium (FIG. 4). "You got a crap body," comments the executioner before killing one of his targets, while the camera indulges on the overweight men's eye-protections, tattoos, and golden chains. These are the only images that emphasize the 
cult of beauty of the Camorra (some of them are having a manicure), and in retrospect we realize that a dark irony permeates them, since later in the film we learn that these people live in a territory devastated by toxic waste. The use of blue light is an evident homage to Blade Runner, in which Scott often adopts a soft frontlight (sometimes a soft uplight with a hard backlight) in order to create its celebrated silhouettes and chiaroscuro effect (Bukatman 1997:29). Soon, the neomelodic Neapolitan music in the background ("Our story seems like a TV animation" coherently goes the song) is covered by the sound of several gunshots. The avenger and his accomplice flee, while the image of the hyperrealist dead bodies lingers until the title of the film appears in purple against a black background. This reproduces the colors of Andy Warhol's Knives that appear on the cover of the Italian edition of the book. In both Saviano and Garrone's works, narrative complexity is mixed with a critical absorption of pop art/culture.

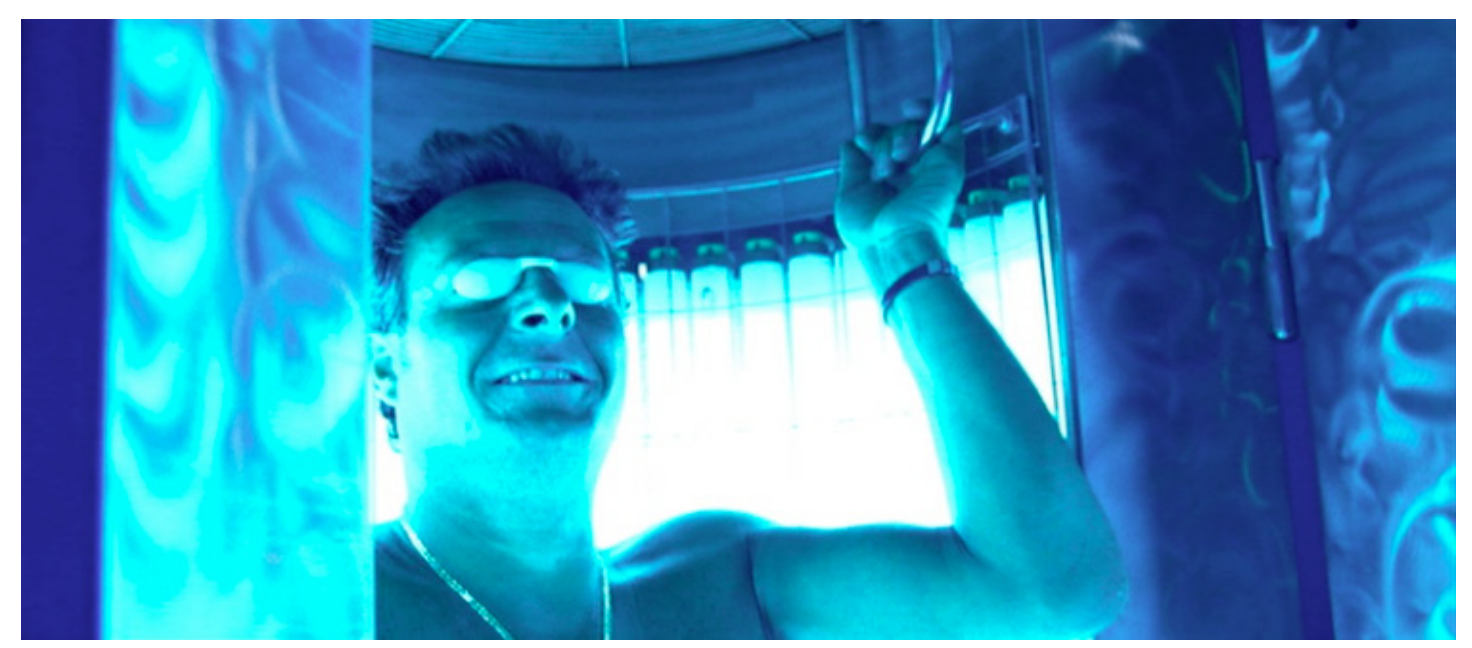

Figure 4. The Camorra avenger in the opening sequence of Gomorrah.

The critic Chuck Stephens emphasized the similarities between the housing project in Scampia and the dystopian architecture of Blade Runner. Creating an at times obvious but effective light and dark symbolism, Garrone stages many scenes within the subterranean structures of "Le Vele," along the apartment-block rooftop gardens, or in the bowels of parking structures. Outside the traditional neorealist time and space, Garrone creates a polycentric and morally ambiguous world in which roads fork, corridors lead to other corridors, and so on in a series of vertiginous symmetries. "Life under Camorra is science fiction - and space, its final frontier," Stephens notes, a concept that is exemplified again when Franco and Roberto emerge after inspecting a cargo container dressed in Hazardous Materials gear (Stephens 2009). In all this, the gaze is not that of the well-informed native Saviano, but that of a witness suddenly injected into the dark side of neocapitalism.

The successes of both the book and the film derive from the sensation that one must understand for the first time something that investigative journalism and cinema has narrated numerous times (Fofi in Non solo Gomorra, 2008:8). At the same time, the movie illuminates the first link of a chain, but there are no names mentioned, and no direct denouncement of the agreements between Camorra and politicians. This does not diminish the impact of the film, since Gomorrah's focus is on the landscape, the bodies and the faces of its non-professional actors, an investigation on the territory that hunts its figurative essence. Rather than describing the state of things as Saviano does, Garrone chooses to describe a non-place that nails the characters to their own destiny. The emotions arise more from an observation of the facts than from the rhetoric artifice of an eyewitness who is omnipresent and judgmental, linking and didactically guiding Camorra's pathways (De Sanctis in Non solo Gomorra, 2008:36). In this sense, Garrone's Gomorrah portrays the contemporary moral impasse of an entire country and is a funeral to easy and consolatory sociological interpretations of the Southern Question and organized criminality. 


\section{Endnotes}

1. Prakash, Gyan, ed. 2010. Noir Urbanism: Dystopic Images of the Modern City. Princeton: Princeton University Press and Dimendberg, Edward. 2004. Film Noir and the Spaces of Modernity. Cambridge: Harvard University Press.

2. See Policardo, Gabriele.2008. Schermi corsari: Pasolini in televisione. Roma: Bulzoni. Another source is the film-montage of the most significant appearances of Pasolini on Italian and French television Il rito del degrado. Pasolini e la televisione (Roberto Chiesi, 2006), available at the Centro Studi-Archivio Pier Paolo Pasolini in Bologna. This document offers a direct cross section of the director's meditations on Italian society in the period 1966-1975.

3. For an overview of recent anti-mafia films see Marcus, Millicent. 2007. "In Memoriam: The Neorealist Legacy in Contemporary Sicilian Anti-Mafia Film.” Pp. 290-306 in L. Ruberto and K. Wilson, eds. Italian Neorealism and Global Cinema. Detroit: Wayne State University Press. 4. In particular The Player (1992), characterized by a rich intertextuality and a dystopic view of Hollywood's generic conventions. Throughout the film, Altman quotes the opening shot of Orson Welles' Touch of Evil (1958), and renders homage to film noir icons such as Humphrey Bogart (who appears on one of the menacing postcards directed to the greedy studio executive Griffin Mill).

5. This term began circulating in relation to Gianni Amelio's Il ladro di bambini (1992). The proliferation of prefixes is self-explanatory in regard to the neorealism's aesthetic impasse.

6. See Jameson, Fredric. 1995. "Totality as Conspiracy" in The Geopolitical Aesthetic: Cinema and Space in the World System. Bloomington: Indiana University Press, 9-84.

\section{References}

Bukatman, Scott. 1997. Blade Runner. London: British Film Institute.

Chion, Michel. 1990. Audio-Vision. New York: Columbia University Press.

De Sanctis, Pierpaolo, Domenico Monetti and Luca Pallanch, eds. 2008. Non solo Gomorra. Tutto il cinema di Matteo Garrone. Cantalupo in Sabina: Edizioni Sabinae.

Garrone, Matteo. 2008. Gomorrah. Perf. Tony Servillo. Fandango.

Fay, Jennifer and Justus Nieland. 2010. Film Noir. Hard-Boiled Modernity and the Cultures of Globalization. New York: Routledge.

Jameson, Fredric. 1993. “The Synoptic Chandler.” Pp. 33 - 56 in Shades of Noir, edited by J. Copjec. New York: Verso.

Larsen, Ernest. 2002. The Usual Suspects. London: British Film Institute.

Ming, Wu. 2009. New Italian Epic. Letteratura, sguardo obliquo, ritorno al futuro. Turin: Einaudi.
Porton, Richard. 2009. "Cineaste Magazine - Articles - Inside "The System": An Interview with Matteo Garrone." Cineaste Magazine - Home. 2009. Web. 23 May 2011. <http://www.cineaste.com/articles/ inside-the-system-an-interview-with-matteo-garrone>.

Redazione online. 2011."A torso nudo con la pistola in mano i baby rapinatori come in Gomorra - Milano." Corriere Milano: Ultime notizie milano e provincia. Corriere Della Sera, 02 Mar. 2011. Web. 23 May 2011. <http://milano. corriere.it/milano/notizie/cronaca/11_marzo_2/baby-gang190132942353.shtml>.

Saviano, Roberto. 2007. Gomorrah. New York: Farrar, Straus and Giroux.

Scorsese, Martin. 1995. A Personal Journey with Martin Scorsese Though American Movies. British Film Institute in Association with Miramax Film.

Schrader, Paul. 1972. "Notes on Film Noir." Pp. 581-591in Film Theory and Criticism, seventh edition, edited by L. Braudy, and M. Cohen. New York: Oxford University Press.

Vernet, Marc. "Film Noir on the Edge of Doom." Pp. 1 - 31 in Shades of Noir, edited by J. Copjec. New York: Verso. 
